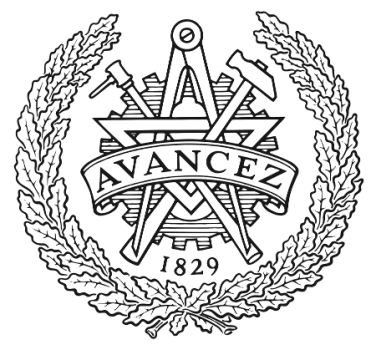

CHALMERS

UNIVERSITY OF TECHNOLOGY

\title{
Effect of the paste-anode interface under impressed current cathodic protection in concrete structures
}

Downloaded from: https://research.chalmers.se, 2023-04-26 11:23 UTC

Citation for the original published paper (version of record):

Zhang, E., Tang, L., Bernin, D. et al (2018). Effect of the paste-anode interface under impressed current cathodic protection in concrete structures. Materials and Corrosion - Werkstoffe und Korrosion, 69(8): 1104-1116. http://dx.doi.org/10.1002/maco.201709908

N.B. When citing this work, cite the original published paper. 


\title{
Effect of the paste-anode interface under impressed current cathodic protection in concrete structures
}

\author{
Emma Q. Zhang ${ }^{1}$ (D) | Luping Tang ${ }^{1}$ | Diana Bernin ${ }^{2}$ | Helén Jansson ${ }^{1}$
}

${ }^{1}$ Department of Architecture and Civil Engineering, Chalmers University of Technology, Sven Hultins gata 6, Gothenborg 412 96, Sweden

${ }^{2}$ Swedish NMR Center, PO Box 465 Gothenburg 40530, Sweden

\section{Correspondence}

Department of Architecture and Civil Engineering, Chalmers University of Technology, Sven Hultins gata 6, Gothenborg 412 96, Sweden.

Email: emma.zhang@chalmers.se

Funding information The Swedish Research Council FORMAS, Grant number: 249-2011-1520; EU Research and Innovation funding program FP7, Project DOSECOPS
Impressed current cathodic protection (ICCP) is a powerful method to prevent and stop corrosion of steel in concrete structures. To evaluate the long-term effect of ICCP, accelerated tests have been adopted using high current densities. A carbon fiber reinforced polymer mesh was introduced as anode. The presented research focused on the changes at the paste-anode interface as a consequence of applying current. The treated samples were characterized by various techniques. Calcium dissolution was found with an average thickness of $0.34 \mathrm{~mm}$ around the anode after charges of $6 \times 10^{6} \mathrm{C} / \mathrm{m}^{2}$ were applied, equivalent to applying $4 \mathrm{~mA} / \mathrm{m}^{2}$ of anode surface for 30 years. Calcium dissolution resulted in a white zone around the anode, where the calcium silica ratio was lowered and almost no crystal phase was observed. NMR results show clear $Q^{3}$ and $Q^{4}$ peaks in the white zone, which contained extended branched and networked structures of hardened cement paste. An increased resistance caused by the formation of the white zone may eventually make the system fail because of insufficient current densities. CFRP has been proven suitable for ICCP application even at a current density of $4 \mathrm{~A} / \mathrm{m}^{2}$ of anode surface.

\section{K E Y W O R D S}

accelerated test, calcium dissolution, cathodic protection, CFRP anode, microstructure, paste-anode interface

\section{1 | INTRODUCTION}

Chloride-induced corrosion of steel reinforcement is a major cause of premature failure for concrete structures. Among the many preventive and protective techniques, impressed current cathodic protection (ICCP) has been proven to be an effective method to prevent and stop corrosion, even in a highly corrosive environment. ${ }^{[1,2,3]}$ In an ICCP system, the protection of the steel is achieved by supplying direct current to the steel bars embedded in the concrete, which induces a cathodic polarization of the steel bars, in other words, it forces the potential to shift to a more negative level, where corrosion can neither initiate nor propagate. ${ }^{[4]}$

It has been intensively studied and well-accepted that ICCP transforms the microstructure of the concrete around the steel over a period of time due to the migration of ionic species and electrochemical reactions. ${ }^{[5,6]}$ However, the effects associated with the anode have not been fully investigated.

It is well-known that if the material of the anode is inert and does not involve electrochemical reactions, the oxidation of hydroxide $\left(\mathrm{OH}^{-}\right)$, and water occur, as given in Reactions (1) and (2). ${ }^{[7]}$ When chlorides are present at the anode site, chlorine gas develops, as shown in Reaction (3).

These reactions contribute to a reduction in $\mathrm{pH}$ at the anode area and involve the dissolution of solids in the hardened cement paste (HCP). Studies have revealed the mechanism of the dissolution: the calcium hydroxide $\left(\mathrm{Ca}(\mathrm{OH})_{2}\right)$ crystals dissolve first, followed by the calcium oxide $(\mathrm{CaO})$ layer in the $\mathrm{C}-\mathrm{S}-\mathrm{H}$ gel, which has been observed in naturally leached and 
carbonated concrete.$^{[8,9]}$ Regarding the dissolution caused by ICCP, microscopic studies have observed an open space with a thickness of 0.02-0.05 mm between the anode and the HCP, which indicates the dissolution of calcium hydroxide crystals. ${ }^{[10]}$ Similar observation has been found in specimens using carbon-based conductive coating anodes. It has also been discovered that the observed amount of dissolution is much lower than the theoretically calculated values, which possibly involves other mechanisms. ${ }^{[11]}$ On a macro-scale level, the dissolution of calcium hydroxide may lead to a loss of adhesion between the anode and the concrete, which can cause the ICCP system to fail earlier than the designed service life. ${ }^{[12]}$ Nonetheless, there have been few studies focused on the anode area. The changes of microstructure in the HCP near the anode, however, are inevitable and are fundamentally important to the performance of ICCP systems. Therefore there is a strong need to investigate the effects and changes at the paste-anode interface.

$$
\begin{gathered}
4 \mathrm{OH}^{-} \rightarrow 2 \mathrm{H}_{2} \mathrm{O}+\mathrm{O}_{2}+4 e^{-} \\
2 \mathrm{H}_{2} \mathrm{O} \rightarrow \mathrm{O}_{2}+4 \mathrm{H}^{+} 4 e^{-} \\
2 \mathrm{Cl}^{-} \rightarrow \mathrm{Cl}_{2}+2 e^{-}
\end{gathered}
$$

In this study a new type of carbon-based anode has also been introduced, which is the carbon fiber reinforced polymer (CFRP) anode. CFRP has excellent conductivity as an anode material and a reinforcing effect on the mechanical properties. ${ }^{[13]}$ Attempts have been made to combine these two functions together, which have demonstrated the successful application of CFRP as anode material for ICCP. ${ }^{[14-16]}$ The CFRP anode can operate at $128 \mathrm{~mA} / \mathrm{m}^{2}$ with a relatively low consumption rate, ${ }^{[17]}$ and the ultimate strength of concrete increases approximately $13.5 \%$ using surface-mounted CFRP fabric. ${ }^{[18]}$ The degradation mechanism of a CFRP anode has been investigated in simulated solutions and a concrete environment. ${ }^{[19-21]}$. Based on their results, the authors in ${ }^{[22,23]}$ suggest that the polymer matrix is sensitive to electrochemical degradation and the carbon fiber remains with very little loss of mass even at very high current densities (up to $3 \mathrm{~A} / \mathrm{m}^{2}$ of anode surface). However, studies of the microstructure at the paste-anode interface are scare.

In order to investigate the long-term effect of an ICCP system over the entire desired service life, for example, from 50 to 100 years, accelerated methods are required to shorten the evaluation time. For the purpose of examining the changes of microstructure in the HCP, high levels of impressed current densities have been adopted. ${ }^{[24]}$ This accelerated method is used to determine the relation between the microstructure changes and the amount of applied charge, and it could be applied in engineering practice.

Hence the present study focuses on the microstructure of the HCP at the anode-paste interface, with the utilization of CFRP as anode. The research presented here has used various characterization techniques with the purpose of clarifying the microstructural changes of the HCP caused by accelerated ICCP at the anode-paste interface.

\section{2 | MATERIALS AND METHODS}

\section{1 | Anode material}

The CFRP anode used in this research was manufactured by SGL Group and is commercially available as SIGRATEX Grid. The dimension of the cross-section of a CFRP bundle was $3.0 \mathrm{~mm}$ in width and $0.6 \mathrm{~mm}$ in thickness. The circumference of a fiber bundle was $15 \mathrm{~mm}$. Each sample contained two bundles of fibers with an effective length of $110 \mathrm{~mm}$, which was buried in cement paste. The total effective anode surface area in each sample was $16 \mathrm{~mm}^{2}$. The measured resistivity per unit length was about $0.05 \Omega$. The type of polymer coating was unknown. The mass percentage of polymer was $15 \%$, as measured by thermogravimetric analysis (TGA).

\subsection{Set-up of the ICCP system}

A lab-scale ICCP system was developed for the purpose of this study. Ordinary Portland cement was used without additives or cement replacement materials. The composition of the Portland cement used in this study is given in Table 1. Cement paste specimens were mixed, with a water cement ratio $(\omega / c)$ of 0.4 , and cast in customized plastic molds. Each specimen contained a single $\Phi 10 \mathrm{~mm}$ plain steel bar as cathode and two bundles of CFRP as anode. The dimension of a specimen is illustrated in Figure 1. All surfaces were coated by epoxy resin to prevent unwanted penetration of chloride, except the curved surface in front of the CFRP anode for one-dimensional chloride penetration. The position of the uncoated surface is shown in Figure 1 as well.

Figure 2 shows an illustration of the experimental setup. Specimens were partially immersed in a $3 \% \mathrm{NaCl}$

\begin{tabular}{|c|c|c|c|c|c|c|c|c|c|}
\hline Chemical composition & $\mathrm{CaO}$ & $\mathrm{SiO}_{2}$ & $\mathrm{Al}_{2} \mathrm{O}_{3}$ & $\mathrm{Fe}_{2} \mathrm{O}_{3}$ & MgO & $\mathrm{Na}_{2} \mathrm{O}$ & $\mathrm{K}_{2} \mathrm{O}$ & $\mathrm{SO}_{3}$ & Cl \\
\hline $\mathrm{wt} \%$ & 64.5 & 22.5 & 3.1 & 4.0 & 1.3 & 0.12 & 0.58 & 2.6 & 0.01 \\
\hline
\end{tabular}
solution during the test. Constant current was applied to the

TABLE 1 Cement composition 


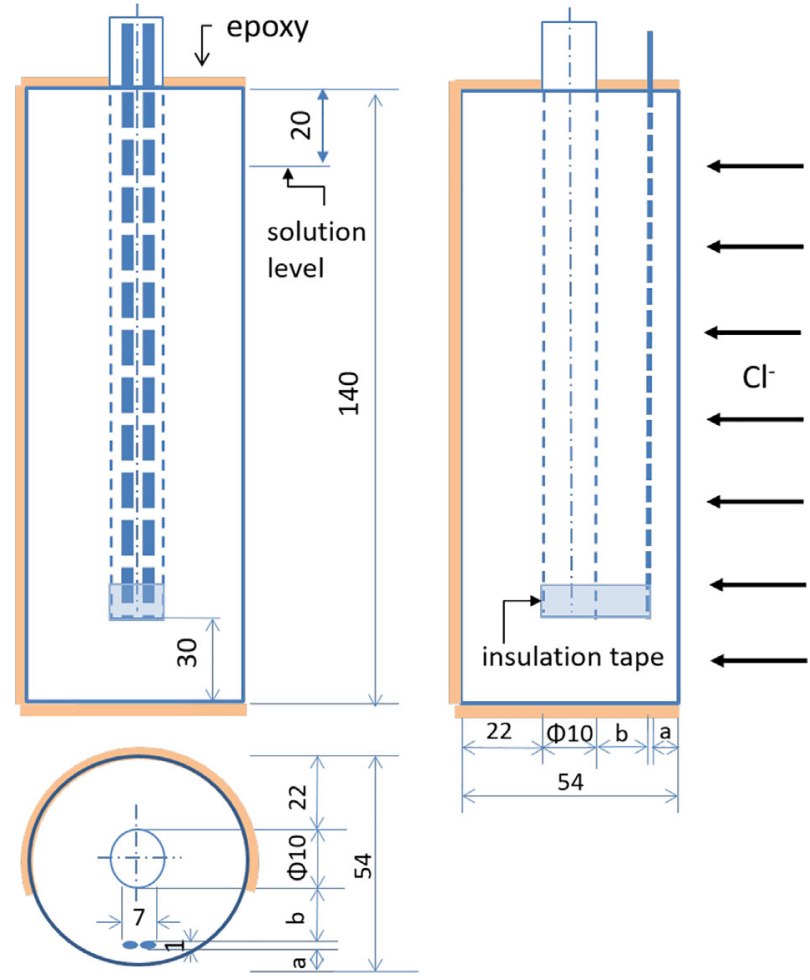

FIGURE 1 A 3-view drawing of the specimen. Chloride penetration direction is indicated by arrows. $\mathrm{a}=7 \sim 10$ and $\mathrm{b}=10 \sim 15$. All values are in mm

specimens by a galvanostatic power supply. The bottom of the steel bars and CFRP anode were wrapped with insulation tape. The current and potential between the cathode (steel) and the anode (CFRP) were monitored over the period of the experiment.

\section{$2.3 \mid$ Accelerated tests}

The principle of an accelerated test is based on the assumption of that the effect of the ICCP is proportional to the total charge applied to the system, referred to as the "total charge density $q$ $\left[\mathrm{C} / \mathrm{m}^{2}\right]$ " in this paper. The total charge density $q$ can be defined by

$$
q=i_{a} \times t_{a}=i_{n} \times t_{n}
$$

where $q$ is the total amount of electrical charge applied to the system per unit area $\left[\mathrm{C} / \mathrm{m}^{2}\right]$, where $C$ is the abbreviation for Coulomb; $i_{a}$, the current density of the cathode surface or anode surface used in the accelerated tests $\left[\mathrm{mA} / \mathrm{m}^{2}\right] ; t_{a}$, the duration of accelerated tests in seconds $[\mathrm{s}] ; i_{n}$, the current density of cathode surface or anode surface in normal CP applications $\left[\mathrm{mA} / \mathrm{m}^{2}\right] ; t_{n}$, estimated service life of normal $\mathrm{CP}$ applications in seconds [s].

As an example, if an accelerated test has been carried out using a current density of $1 \mathrm{~A} / \mathrm{m}^{2}$ for 10 days, the result of this

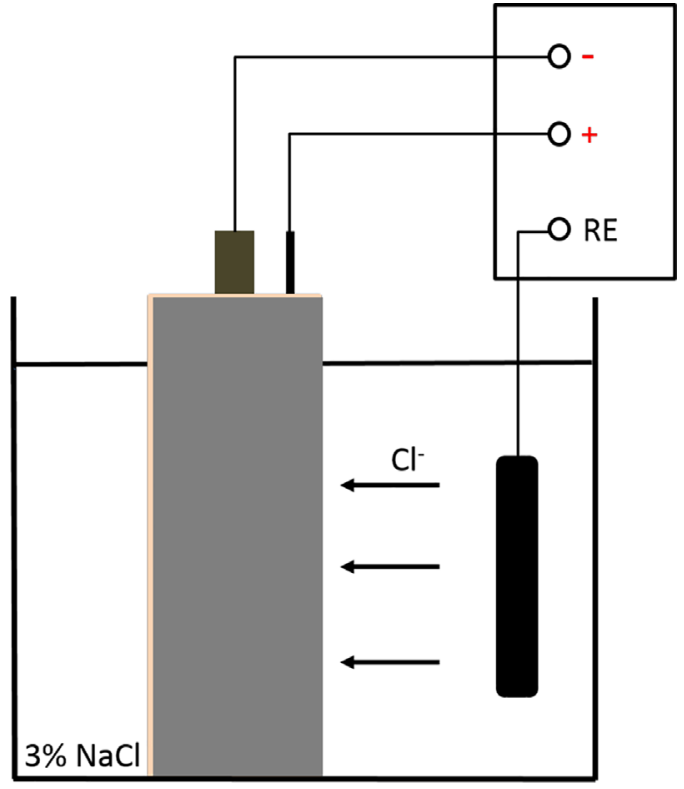

FIGURE 2 Experimental arrangement of the ICCP system. Steel as cathode is connected to negative terminal ( - ) and CFRP as anode is connected to positive terminal (+). RE represents the reference electrode. The direction of chloride penetration is indicated by arrows

accelerated test could be used to evaluate $\mathrm{CP}$ operation at a current density of $10 \mathrm{~mA} / \mathrm{m}^{2}$ for 1,000 days.

The advantage of accelerated tests is obviously the shortened experimental time when dealing with a long-term experiment such as 50 years. However, there are also some side effects. Excessive applied current could cause unnecessary corrosion or damage to the cable connections. Samples are more sensitive to defects such as air voids or cracks because they can dramatically alter the distribution of current. Moreover, due to limitations of sample size and quantity, the uncertainty of the results therefore also increases. Because of the possible effects brought about by acceleration, the predicted service life $\left(t_{n}\right)$ is generally underestimated, which in fact is more conservative for engineering use of the method.

Table 2 gives the details of the experiments. It should be noted that the current densities used in this experiment were 20 and 40 times higher than the recommended maximum current density for cathodic protection $\left(108 \mathrm{~mA} / \mathrm{m}^{2}\right.$ recommended by NACE Standard Practice). ${ }^{[25]}$ This could cause the early deterioration of some of the samples due to spalling and electrical connections.

The intended total charge density was $5.7 \times 10^{6}$ and $10 \times 10^{6} \mathrm{C} / \mathrm{m}^{2}$ for Acc3 and Acc6 group, respectively. However, due to the fluctuation of the applied current, the actual applied total charge density was lower than expected. For the Acc3 group, the actual $q$ almost reached the desired level, while for the Acc6 group, it was only about 55\% of the desired amount of charge applied to the samples. The estimated service life, if $i_{n}$ were $4 \mathrm{~mA} / \mathrm{m}^{2}$, would be between 40 and 50 years for all samples. 
TABLE 2 Experimental program of accelerated tests

\begin{tabular}{lllllll} 
Sample ID & $\boldsymbol{I}(\mathbf{m A})$ & $\boldsymbol{i}\left(\mathbf{A} / \mathbf{m}^{\mathbf{2}}\right)$ & $\boldsymbol{t}_{\boldsymbol{a}}(\mathbf{d a y})$ & $\boldsymbol{Q}(\mathbf{C})$ & $\boldsymbol{q}\left(\mathbf{C} / \mathbf{m}^{\mathbf{2}}\right)$ & $\boldsymbol{t}_{\boldsymbol{n}}^{\mathbf{d}}(\mathbf{y e a r})$ \\
Acc3-a & 3 & 2.1 & $35^{\mathrm{a}}$ & 8133 & $5.1 \times 10^{6}$ \\
Acc3-b & 3 & 2.1 & $37^{\mathrm{c}}$ & 8144 & $5.1 \times 10^{6}$ & 40 \\
Acc6-a & 6 & 4.0 & $35^{\mathrm{b}}$ & 9886 & $6.2 \times 10^{6}$ \\
Acc6-b & 6 & 4.0 & $37^{\mathrm{c}}$ & 8584 & $5.2 \times 10^{6}$ \\
\hline
\end{tabular}

${ }^{\mathrm{a}}$ Experiment terminated due to surface cracks and spalling.

${ }^{\mathrm{b}}$ Experiment terminated due to damage to anode-cable connection.

${ }^{\mathrm{c}}$ Experiment terminated as planned.

${ }^{\mathrm{d}}$ When $i_{n}$ equals $4 \mathrm{~mA} / \mathrm{m}^{2}$.

\subsection{Image analysis}

Samples were sliced in the direction perpendicular to the anode. An image analysis of the paste-anode interface was done by an image processing program. As shown in Figure 3, the area of dissolution can be distinguished by colors and defined by free-shape selection. After the area was selected, the value was calculated automatically with a pre-defined spatial scale.

Because the shapes of the dissolution areas were irregular and different at each location, the dissolution thickness $\Delta d$ was characterized by

$$
\Delta d=\frac{A}{C}
$$

where $A$ is the area of dissolution and $C$ is the perimeter of the anode cross-section.

\subsection{Microstructure and chemical analysis}

After the accelerated tests, the treated specimens were prepared for topographical and chemical analysis. Topography imaging and elemental analysis were carried out by a scanning electron microscope with energy dispersive $\mathrm{X}$-ray spectroscopy (SEM-EDS). The determination of the distribution of chemicals over the cross-section of specimens was carried out by laser ablation-inductively coupled plasma-mass spectroscopy (LA-ICP-MS) using line-scanning mode.

The analyses of the crystal phases and molecular interactions were conducted by X-ray diffraction (XRD) and nuclear magnetic resonance (NMR), respectively. Powder samples were extracted from the white zone by carefully scraping them from the bulk specimen. The collected powder was ground and stored in a $\mathrm{CO}_{2}$-free environment.

\subsection{1 | SEM-EDS}

The topography of the polished samples was analyzed with by scanning electron microscopy (SEM). An FEI Quanta ESEM 200 equipped with a field emission gun and an Oxford Inca EDS system was used to perform the analysis. The samples were vacuum dried and fine polished prior to analysis. The elemental compositions were examined by the integrated energy dispersive spectrometer (EDS) in a high vacuum mode. The detection limits were about $0.1 \%$ with EDS $(1,000 \mathrm{ppm})$. The accelerating voltage was $15-20 \mathrm{kV}$.

\subsection{2 | LA-ICP-MS}

Laser ablation-inductively coupled plasma-mass spectroscopy quantified the longitudinal changes in the distribution of

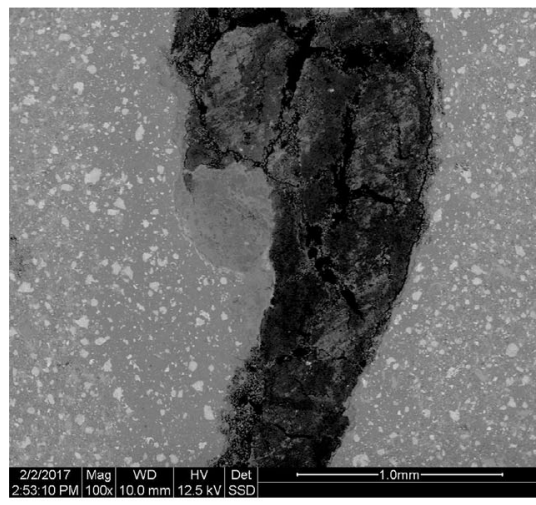

(a) Original

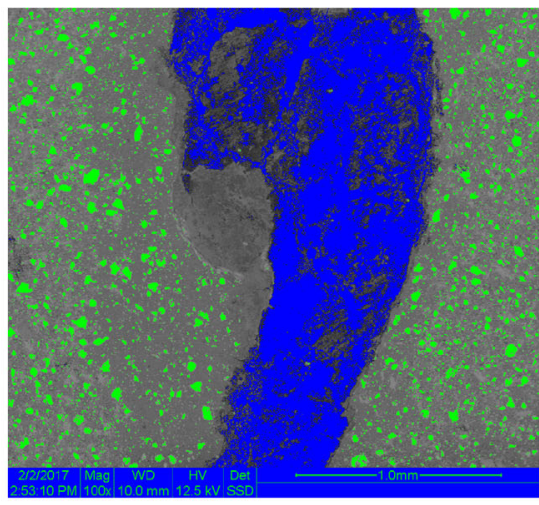

(b) Color-scale

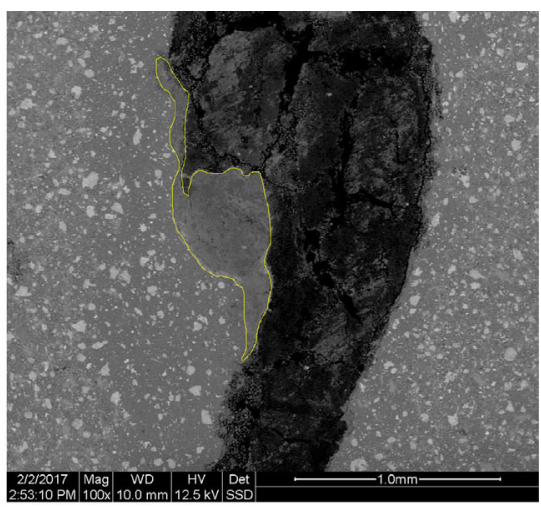

(c) Selected area

FIGURE 3 Image analysis of the dissolution area 
elements. The laser ablation analysis was performed using a New Wave NWR213 laser ablation system coupled to an Agilent 7500a quadrupole ICP-MS.

A large format cell held samples up to a size of $10 \mathrm{~cm} \times 10 \mathrm{~cm}$, combined with a $1 \mathrm{~cm}$ diameter ablation chamber at the ablation region, enabling fast washout anywhere in the sample chamber. A $30 \mu \mathrm{m}$ laser spot size, beam energy density of about $6 \mathrm{~J} / \mathrm{cm}^{2}$, and a repetition rate of $10 \mathrm{~Hz}$ was used in line-scanning mode (scan speed $60 \mu \mathrm{m} / \mathrm{s}$ ). The samples were dried and fine polished prior to measurements.

Calibration was performed by frequently measuring the glass standard SRM NIST 610 using the values of Jochum et al. ${ }^{[26]}$ Each measurement consisted of $30 \mathrm{~s}$ background followed by $400 \mathrm{~s}$ of signal collection. Dwell times were $20 \mathrm{~ms}$.

\subsection{3 | NMR}

${ }^{29} \mathrm{Si}$ solid state NMR under magic angle spinning (MAS) was used to gain information about the present silicate species. Single pulse experiments with an excitation pulse of $25^{\circ}$ and a repetition time of $30 \mathrm{~s}$ were recorded at an MAS rate of $15 \mathrm{kHz}$ using a $3.2 \mathrm{~mm}$ double resonance MAS probe at 14.7 $\mathrm{T}$ (Agilent Inova).

It is well-established that a ${ }^{29} \mathrm{Si}$ spectrum of the silicate anion is represented in the range of -70 to $-76 \mathrm{ppm}$ for $Q^{0}$ (monomer), -78 for $Q^{1}$ (dimer or end group in a chain), -81 to -85 for $Q^{2}$ (chain), -93 to -102 for $Q^{3}$ (branched structure), and -107 to -115 for $Q^{4}$ (networked structure). ${ }^{[9,27,28]}$ The average degree of C-S-H connectivity $\bar{n}$ is calculated as follows, ${ }^{[29]}$

$$
\bar{n}=\frac{Q^{1}+2 Q^{2}+3 Q^{3}}{Q^{1}+Q^{2}+Q^{3}} .
$$

A higher value of $\bar{n}$ represents a higher degree of polymerization of the $\mathrm{C}-\mathrm{S}-\mathrm{H}$. The mean chain length (MCL) or number of $\mathrm{SiO}_{4}$ tetrahedra in the C-S-H can be calculated from Richardson's equation, ${ }^{[30]}$

$$
\mathrm{MCL}=\frac{2 \times Q^{1}+Q^{2}}{Q^{1}},
$$

where the relative proportions of silicon associated with the $Q^{n}$ units were determined by deconvolution of the spectra and measurement of the area associated with each peak using a curve-fitting technique.

\subsection{4 | XRD}

Characterization of crystalline phases in the cement paste was carried out by XRD analysis. The measurements were performed by using $0.015^{\circ}$ per step and a time step of $12 \mathrm{~s}$, resulting total measurement time of each sample was about $24 \mathrm{~h}$.

\section{3 | RESULTS AND DISCUSSION}

\section{1 | Potential monitoring}

Figure 4 illustrates the changes in the potential $\left(\varphi_{\text {cell }}\right)$, current $(I)$, and total resistance $\left(R_{t}\right)$ over time. The total resistance $R_{t}$ was calculated as the potential divided by the current as given in Equation (8), where $\varphi_{\text {water }}$ was the potential of water electrolysis and the value was 1.229 at $\mathrm{pH}$ of $14 . R_{t}$ was a sum of three components: the surface resistance at the anode $\left(\eta_{\mathrm{san}}\right)$, that at the cathode $\left(\eta_{\text {scat }}\right)$ (both of which were induced by polarization), and the mixed resistance $\eta_{p}$ of the paste (which was relatively stable).

$$
R_{t}=\frac{\varphi_{\text {cell }}-\varphi_{\text {water }}}{I}=\eta_{\text {san }}+\eta_{\text {scat }}+\eta_{p}
$$

The development of $I$ and $\varphi_{\text {cell }}$ of four samples followed the same pattern. Here, only the specimen Acc6-a will be discussed, as an example.

Figure $4 \mathrm{c}$ shows that $\varphi_{\text {cell }}$ increased almost immediately after polarization and reached its maximum potential after ten days. The current $i$ stayed at $6.4 \mathrm{~mA}$ as planned for about 10 days and then began to change. The current continued to drop. However, unexpectedly, it increased again between day 15 and day 25. After that, the current decreased gradually and remained at a low point of $0.6 \mathrm{~mA}$ for 3 days before the experiment was terminated due to cable damage. A possible explanation of this phenomenon between day 15 and day 25 is that the conductivity of the pore solutions was increased because of the accumulation of chloride ions and at the same time the solubility of the calcium also increased because of there being chloride ions instead of hydroxide ions. However, chloride ions can form chlorine gas and escape from the system, which leads to the decrease of conductivity again.

Over 35 days of the accelerated test, the total charge density passed through was $6 \times 10^{6} \mathrm{C} / \mathrm{m}^{2}$ of the anode surface, which was equal to $40.5 \mathrm{~mol} / \mathrm{m}^{2}$ of electrons produced at the anode. $R_{t}$ of Acc6-a was enlarged about 130 times, from originally $220 \Omega$ to $2.8 \times 10^{5} \Omega$ by the end of the experiment, which indicated chemical changes of the HCP and of the pore solutions. This increase of resistivity would lower the efficiency of the ICCP and might eventually cause the ICCP to fail because the protective current density would become insufficient. However, in this experiment, the specimen Acc6-a, for example, having been maintained at $0.6 \mathrm{~mA}$ until terminated, still experienced a current density of $37.5 \mathrm{~mA} / \mathrm{m}^{2}$, which was sufficient for protection. 


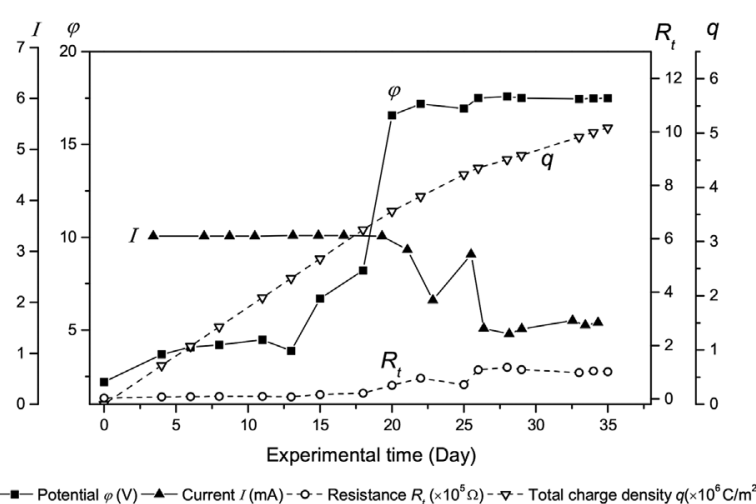

(a) Acc3-a

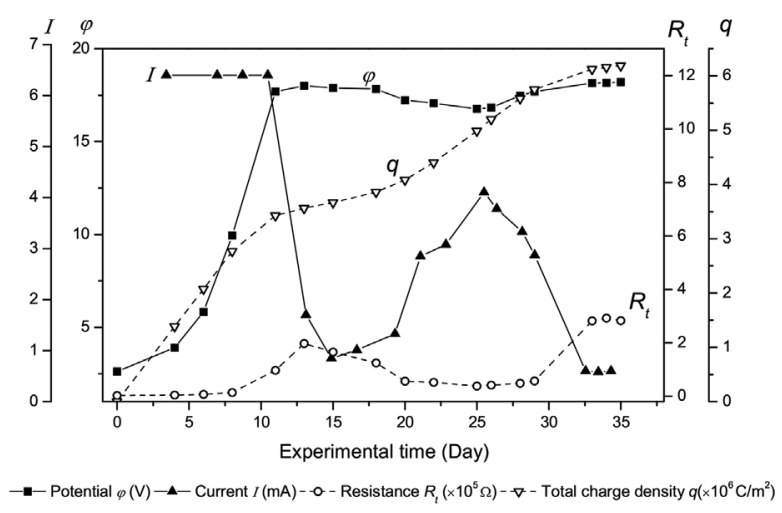

(c) Acc6-a

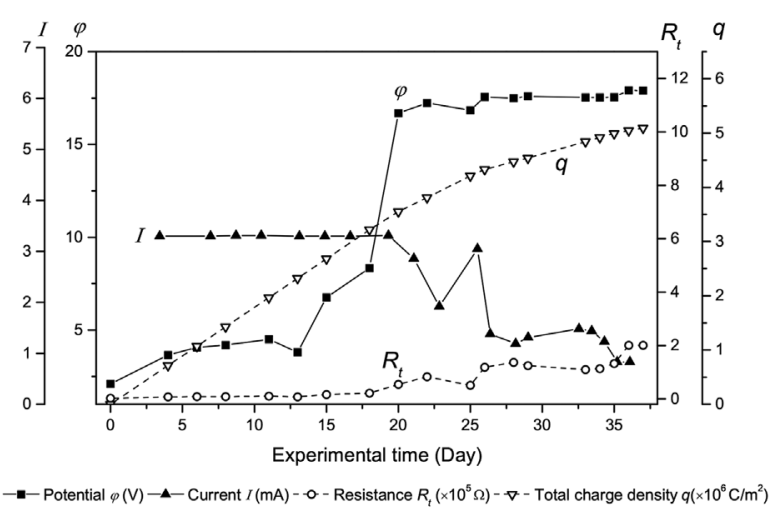

(b) Acc3-b

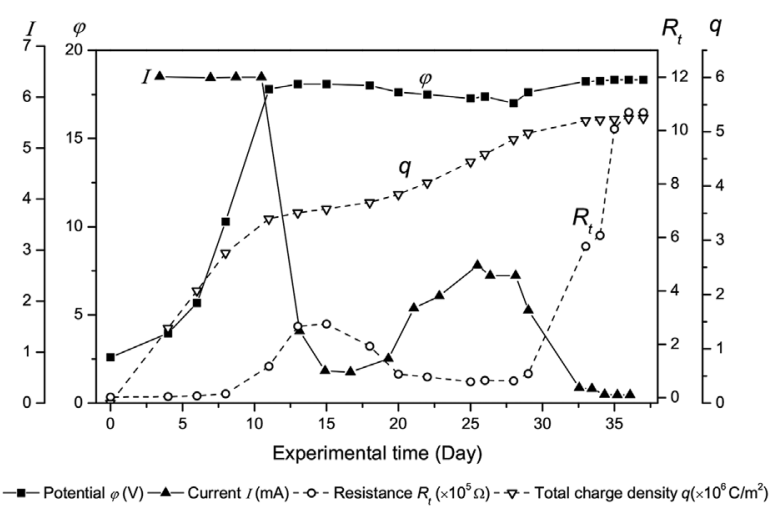

(d) Acc6-b

FIGURE 4 Monitoring of the potential and current of treated specimens. Calculated total resistance and total charge density are also listed. (a) Acc3-a; (b) Acc3-b; (c) Acc6-a; and (d) Acc6-b

Using the accelerated test to evaluate the long-term ICCP effect, the overall consequence of a total charge density of $6 \times 10^{6} \mathrm{C} / \mathrm{m}^{2}$ (of the anode surface) would give a similar result to that of constantly applying $4 \mathrm{~mA} / \mathrm{m}^{2}$ (to the anode surface) for 30 years, calculated as in Equation (4). A linear relation between the accelerated tests and normal operations was adopted in the analysis. It is worth mentioning that the specimen was still under sufficient protection when it was terminated, therefore the actual service life should be longer.

\subsection{Phase changes in the HCP around anode}

Since all four samples showed similar patterns, in this paper only the results from sample Acc6-a will be presented, as an example.

Figure 5 shows a new phase of white color formed around the anode in the HCP. The size of the white zone increased along the $y$-axis of the specimen, that is, the white zone was either not visible, or very small, in the lower part of the specimen, while it appeared the greatest at the top.

It was clear that the ICCP caused a phase change around the anode due to mass transport and electrochemi- cal reactions. The phase change was not evenly distributed along the anode, possibly because of the inhomogeneity of the HCP leading to an unevenly distributed electrical field. Moreover, the top part of the specimen has the shortest electrical path, implying the lowest resistance and resulting in the greatest zone of phase change, while the lower part is the opposite.

Figure 6 shows the image analysis of the paste-anode interface, to which correspond images B-D in Figure 5. The three heights were chosen to represent the top, the middle, and the bottom part of a sample. The calculated areas of dissolution (highlighted area) are $6.9,0.3$, and $2.4 \mathrm{~mm}^{2}$, at heights of 20,59, and $80 \mathrm{~mm}$, respectively. Table 3 gives a summary of all measured values of the areas and thicknesses of the four samples.

Figure 7 summarizes the dissolution thickness. The solution level was at the height of $25 \pm 5 \mathrm{~mm}$. Most of the calcium dissolution took place at and above the solution level. Below the solution level, the white zones tended to be small and evenly distributed. The Acc3 group showed a better pattern than the Acc6 group, implying that a current density of $4 \mathrm{~A} / \mathrm{m}^{2}$ could cause extra damage and increase the uncertainty of the results. 


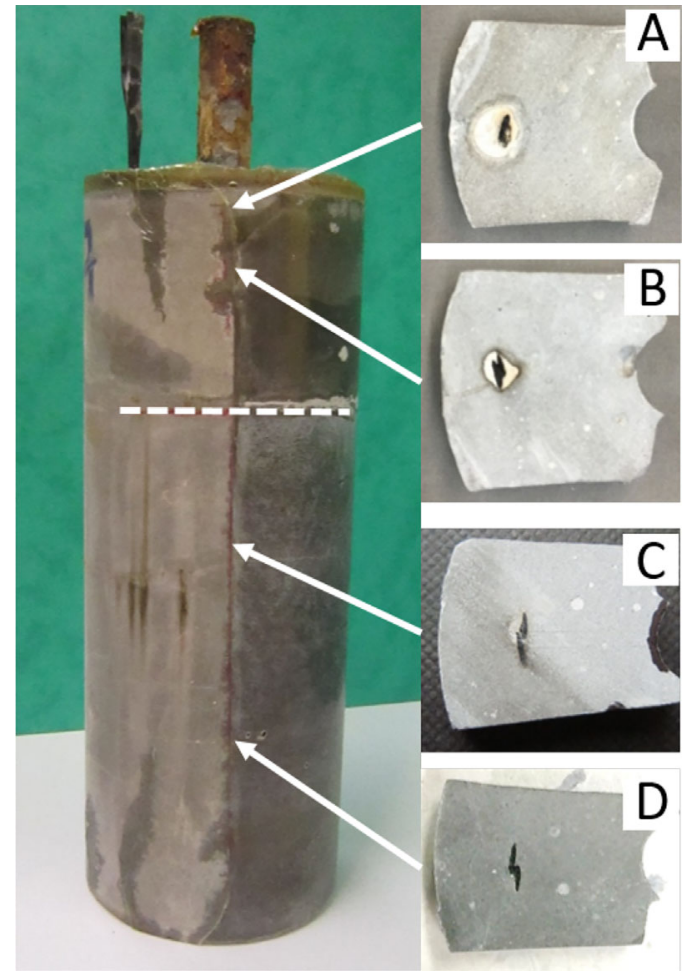

FIGURE 5 Image on the left shows the treated specimen Acc6-a, containing two bundles of CFRP anode and a steel bar. Images A-D show the white zone formed around the anode, which is black. Dashed line indicates the solution level. Arrows indicate the height where samples were taken

\section{3 | Change of $\mathrm{C} / \mathrm{S}$ ratio}

Table 4 lists the measured C S ratios by SEM-EDS and LA-ICP-MS and Figure 8 shows line-scanning results by LA-ICP-MS. The line-scanning mode was able to examine the cross-sections of the samples and provided evidence of changes in the $\mathrm{C} / \mathrm{S}$ ratio across the crosssections.

The C/S ratio of reference samples in tap water and in salt solution were measured. The results obtained by
SEM-EDS were generally lower than those from LAICP-MS. However, within each sample, the consistency of the measured values was relatively good. These make the SEM-EDS results suitable for comparison within one sample, while the LA-ICP-MS measurements were appropriate both for analysis within one and among several samples.

For the accelerated sample Acc6-a, the C/S ratio of the unaffected zone was in good agreement with those of the reference samples. The $\mathrm{C} / \mathrm{S}$ ratios of the white zone were smaller than those in the unaffected zone, according to both measuring techniques. The results from LA-ICP-MS gave a profile changing against the distance from the exposure surface, with the lowest value of 1.0 on average on the fitted curve at the position close to the anode, which was smaller than that obtained by SEM-EDS.

Table 5 lists the fitting parameters and the calculation of the degree of dissolution of three samples from specimen Acc6-a. The fitted curves of $\mathrm{C} / \mathrm{S}$ ratios (dashdot line in Figure 8) were analyzed to calculate the degree of calcium dissolution. The dissolution degree (DD) of $\mathrm{CaO}$ in the white zone was defined as in Equation (9) and used to describe how much calcium was leached out by ICCP. The DD was $41 \%$ on average of three measurements, which indicates that there was about $38 \%$ of $\mathrm{CaO}$ remaining in the composition of the white zone, compared to $65 \%$ originally in the cement.

It is worth mentioning that the area of dissolution $(A)$ can be represented either by the whole peak (in Figure 8a) or onehalf of the peak (in Figure 8b,c), depending on the location of the CFRP anode. Therefore the local dissolution thickness can be either $2 \omega$ or $\omega$.

The local dissolution thickness $\omega$ of Acc6-a-H59 also measured by image analysis and length of visible dissolution thickness was $0.67 \mathrm{~mm}$ as marked by the arrow in Figure $6 \mathrm{~b}$. This value was in good agreement with the LA-ICP-MS measurement and reasonable since a small degree of calcium

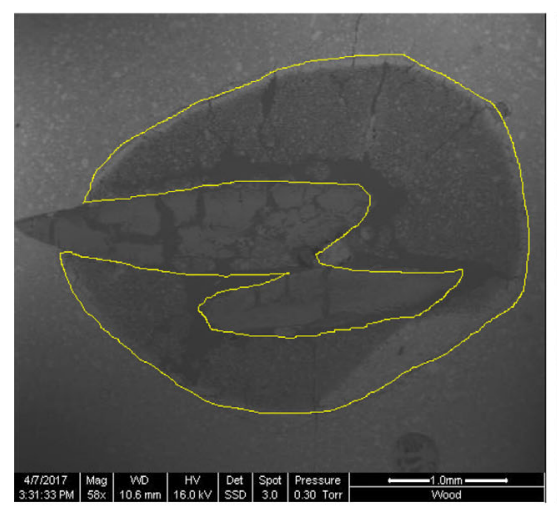

(a) Acc6-a-H20

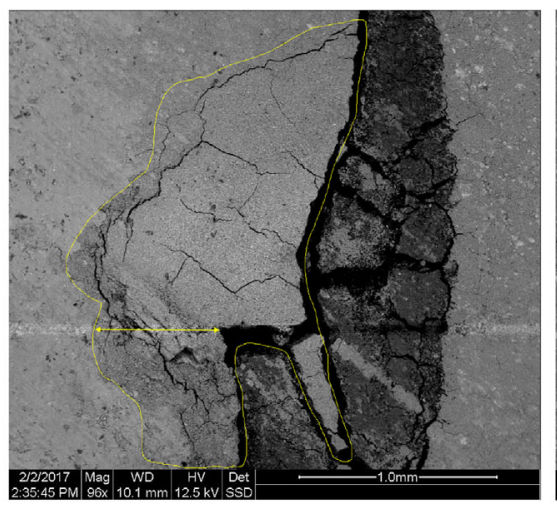

(b) Acc6-a-H59

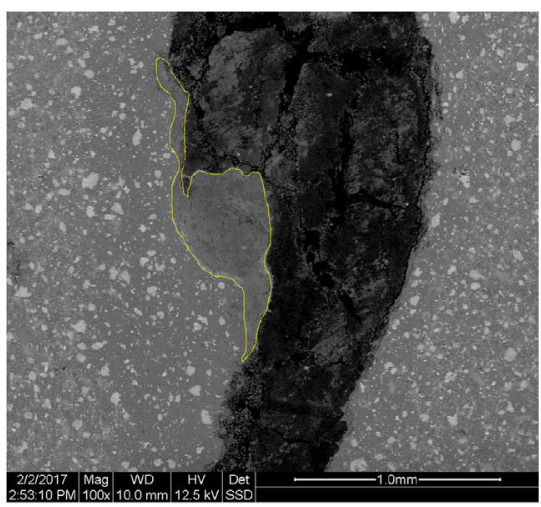

(c) Acc6-a-H80

FIGURE 6 SEM images of Acc6-a at different heights. (a) Acc6-a-H20; (b) Acc6-a-H59; and (b) Acc6-a-H80 
TABLE 3 Measured phase change zone and dissolution thickness for sample Acc3 and Acc6

\begin{tabular}{|c|c|c|c|c|c|c|c|c|}
\hline Height (mm) & \multicolumn{2}{|l|}{ Acc3-a } & \multicolumn{2}{|l|}{ Acc3-b } & \multicolumn{2}{|l|}{ Acc6-a } & \multicolumn{2}{|l|}{ Acc6-b } \\
\hline 3 & 21.4 & 1.47 & 25.9 & 1.78 & 22.9 & 1.58 & 4.9 & 0.34 \\
\hline 12 & 12.2 & 0.84 & 9.0 & 0.62 & 6.4 & 0.44 & 9.9 & 0.68 \\
\hline 17 & 10.8 & 0.75 & 7.9 & 0.54 & 4.1 & 0.28 & 11.6 & 0.80 \\
\hline 26 & 7.2 & 0.50 & 4.2 & 0.29 & 1.4 & 0.09 & 4.1 & 0.28 \\
\hline 29 & 3.1 & 0.21 & 2.5 & 0.17 & 1.3 & 0.95 & 4.8 & 0.33 \\
\hline 35 & 1.3 & 0.09 & 1.9 & 0.13 & 0.3 & 0.02 & 4.0 & 0.28 \\
\hline 38 & 3.7 & 0.26 & 4.2 & 0.29 & 2.0 & 0.14 & 4.4 & 0.30 \\
\hline 55 & 1.2 & 0.08 & 1.0 & 0.07 & 0.9 & 0.06 & 7.8 & 0.54 \\
\hline 59 & 1.6 & 0.11 & 1.7 & 0.11 & 2.4 & 0.16 & 2.4 & 0.17 \\
\hline 62 & 0.6 & 0.04 & 1.3 & 0.09 & 2.2 & 0.15 & 5.7 & 0.39 \\
\hline 68 & 1.1 & 0.08 & 2.3 & 0.16 & 1.1 & 0.08 & 4.6 & 0.32 \\
\hline 71 & 1.0 & 0.07 & & & 4.0 & 0.28 & 7.6 & 0.52 \\
\hline 77 & 1.1 & 0.08 & 1.6 & 0.11 & 1.0 & 0.07 & 1.7 & 0.12 \\
\hline 80 & 1.0 & 0.07 & 2.3 & 0.16 & 0.5 & 0.02 & 8.5 & 0.59 \\
\hline 86 & 0.7 & 0.05 & & & 1.5 & 0.10 & 3.5 & 0.24 \\
\hline
\end{tabular}

The bold values signify the average value of all the measurements.

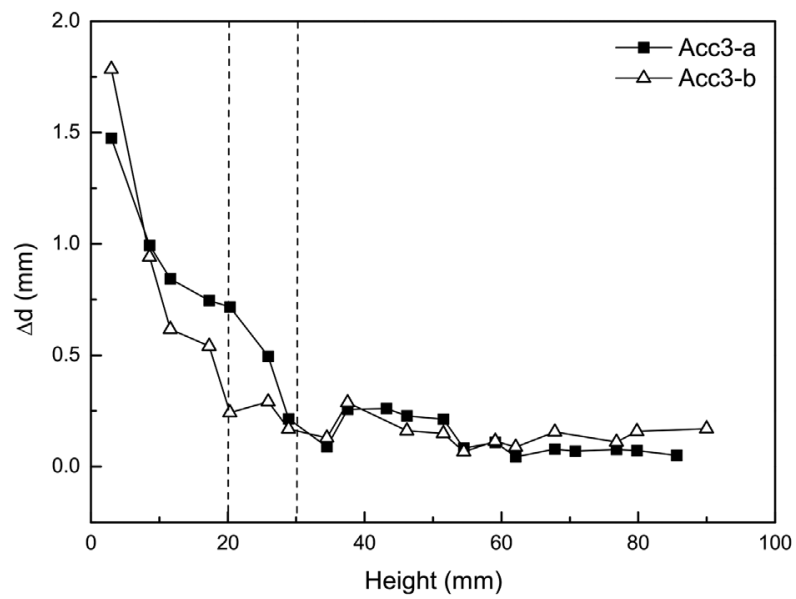

(a) Acc3 group

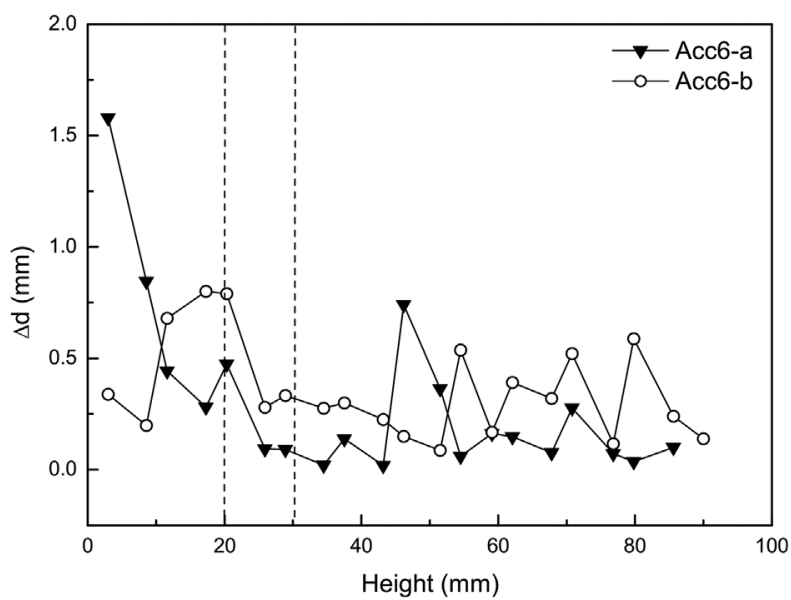

(b) Acc6 group

FIGURE 7 Dissolution thickness of Acc3 and Acc6 group. Dashed lines indicate the solution level, which varies between 20 and 30 mm from the top. (a) Acc3 group and (b) Acc6 group 
TABLE 4 Measured C/S ratios in reference and accelerated samples

\begin{tabular}{|c|c|c|c|}
\hline Samples & $\begin{array}{l}\text { LA-ICP- } \\
\text { MS }\end{array}$ & $\begin{array}{l}\text { SEM-EDS } \\
\pm \text { St.Dev. }\end{array}$ & Comment \\
\hline Ref in tap water & 3.1 & $2.9 \pm 0.8$ & $\begin{array}{l}\text { Avg. of } 35 \\
\text { points }\end{array}$ \\
\hline $\begin{array}{l}\text { Ref in salt } \\
\text { solution }\end{array}$ & 3.1 & $2.3 \pm 0.7$ & $\begin{array}{l}\text { Avg. of } 55 \\
\text { points }\end{array}$ \\
\hline $\begin{array}{l}\text { Acc6-a } \\
\text { unaffected } \\
\text { zone }\end{array}$ & 3.2 & $2.5 \pm 0.9$ & $\begin{array}{l}\text { Avg. of } 24 \\
\text { points }\end{array}$ \\
\hline $\begin{array}{l}\text { Acc6-a-H20 } \\
\text { white zone }\end{array}$ & 0.9 & & \\
\hline $\begin{array}{l}\text { Acc6-a-H43 } \\
\text { white zone }\end{array}$ & 0.8 & & \\
\hline $\begin{array}{l}\text { Acc6-a-H59 } \\
\text { white zone }\end{array}$ & 1.3 & $2.1 \pm 0.1$ & $\begin{array}{l}\text { Avg. of } 26 \\
\text { points }\end{array}$ \\
\hline
\end{tabular}

LA-ICP-MS is in line-scanning mode. Results from SEM-EDS are presented by average values \pm standard deviation.

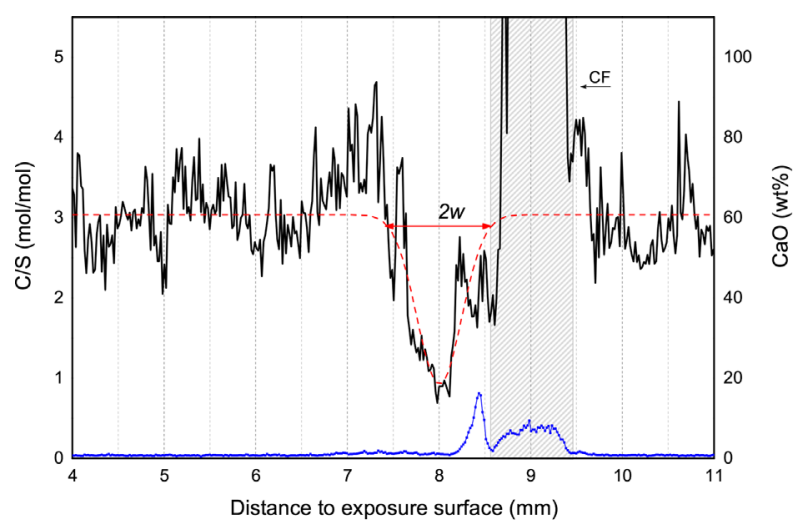

- Acc6 C/S --- Acc6 C/S fitted - - Acc6 Carbon (indicative)

(a) Acc6-a-H20

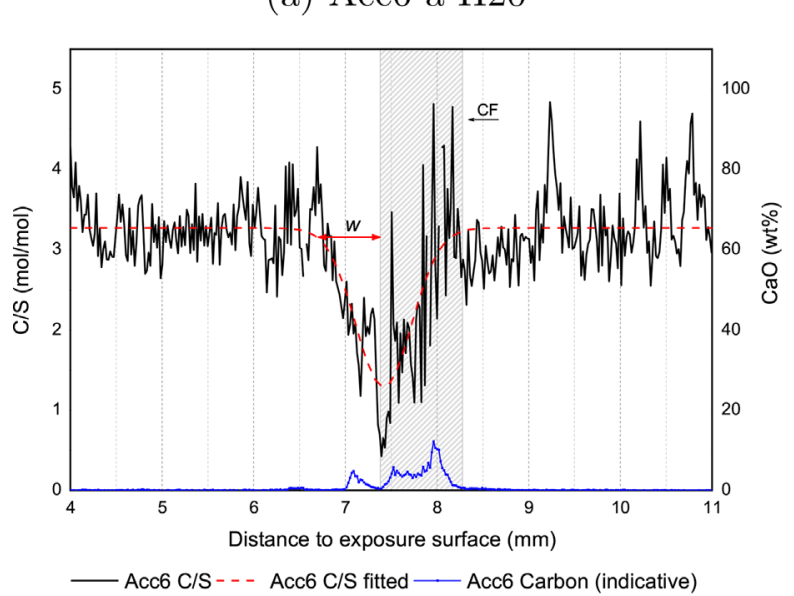

(c) Acc6-a-H59 dissolution may not be enough to alter the color, but yet enough to be detected by an analytic instrument.

$$
\mathrm{DD}=\frac{\text { content of dissolved calcium }}{\text { content of original calcium }}
$$

\subsection{Characterization of the white zone}

Figure 9 illustrates the XRD analysis of the powders extracted from the reference and the white zones. The most apparent change between the reference and the white zones was the disappearance of Portlandite peaks and C-S-H peaks in the white zone. This is because C-S-H gel phases were poorly crystallized, so they generally can be characterized in $2 \theta$ of $29^{\circ}$ to $33^{\circ}$ and about $51^{\circ} .{ }^{[31]} \mathrm{C}-\mathrm{S}-\mathrm{H}$ gel phases presented in the reference sample had almost disappeared in the white zone, indicating a high degree of calcium depletion and that mostly an amorphous silica-gel-like phase had formed. The

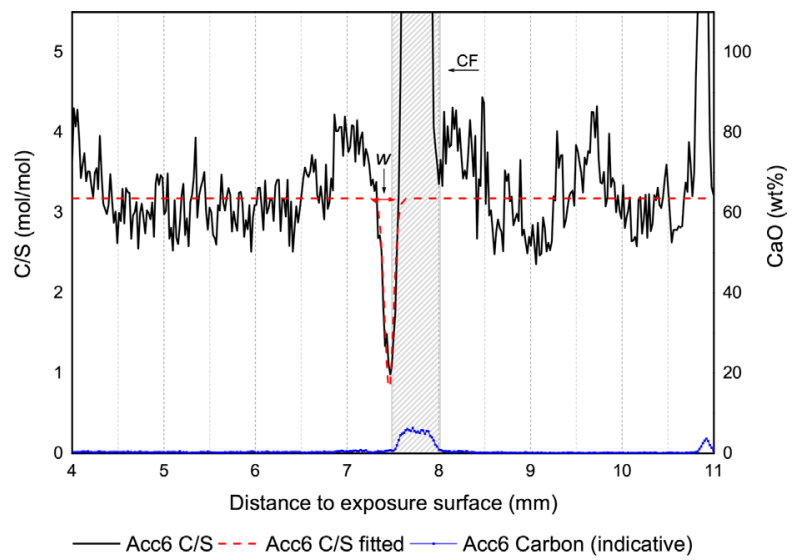

(b) Acc6-a-H43 
TABLE 5 Fitting and calculation of calcium dissolution degree

\begin{tabular}{|lllll|}
$\begin{array}{l}\text { Fitting and } \\
\text { calculation }\end{array}$ & & $\begin{array}{l}\text { Acc6- } \\
\mathbf{a - H 2 0}\end{array}$ & $\begin{array}{l}\text { Acc6- } \\
\mathbf{a - H 4 3}\end{array}$ & $\begin{array}{l}\text { Acc6- } \\
\mathbf{a - H 5 9}\end{array}$ \\
\hline Area & $A$ & 1.39 & 0.30 & 1.51 \\
\hline Center & $x c$ & 8.01 & 7.46 & 7.42 \\
\hline Width & $\omega$ & 0.50 & 0.10 & 0.72 \\
\hline Height & $h$ & 2.19 & 2.37 & 1.98 \\
\hline Baseline & $y 0$ & 3.12 & 3.18 & 3.27 \\
\hline $\begin{array}{c}\text { Area of } \\
\text { original } \\
\text { calcium }\end{array}$ & $A_{0}=y 0 \times 2 \omega$ & 3.17 & 0.63 & 4.69 \\
\hline $\begin{array}{c}\text { Dissolution } \\
\text { degree }\end{array}$ & $D D=\frac{A}{A_{0}}$ & $43.9 \%$ & $46.8 \%$ & $32.3 \%$ \\
\hline
\end{tabular}

major identified crystalline phase in the treated sample was gypsum, which was induced by the cement manufacturing process.

Powder from the white zone was also examined by NMR analysis to provide information of the $\mathrm{Si}$ environment on an atomic scale. Figure 10 illustrates the chemical shift in the reference and the white-zone sample. As expected, in the reference sample only $Q^{1}$ (chain end) and $Q^{2}$ (within chain) peaks were visible, and neither $Q^{3}$ or $Q^{4}$ were observed, since chain structures were the major constituents in HCP. ${ }^{[28]}$ However, in the white zone, clear $Q^{3}$ and $Q^{4}$ peaks were observed, which indicated that branched and networked structures were formed due to a high degree of calcium depletion.

The calculated connectivity $\bar{n}$ for the reference sample was 1.4 and for the white-zone powder was 2.1, indicating higher polymerization of C-S-H and a lower $\mathrm{C} / \mathrm{S}$ ratio, ${ }^{[32]}$ which were confirmed by SEM-EDS and LA-ICP-MS in section 3.3. The average MCL for the reference and the white-zone sample

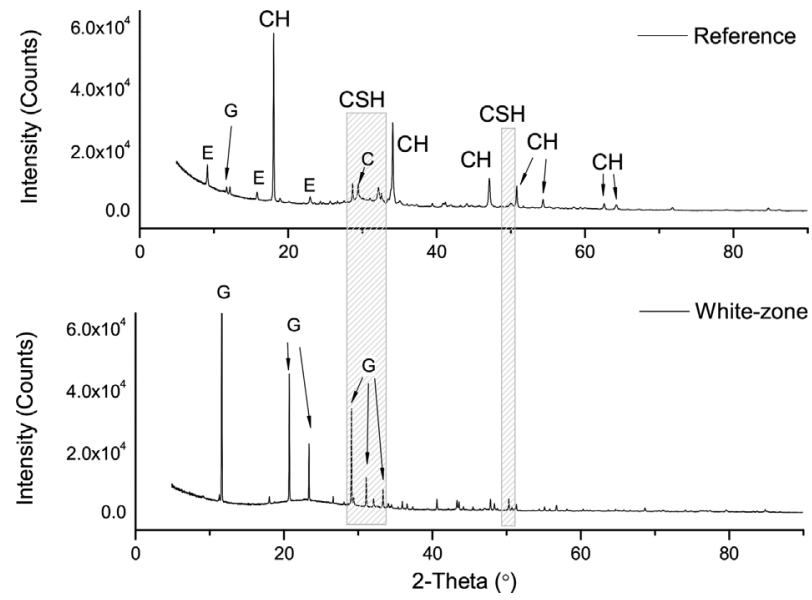

FIGURE 9 X-ray diffraction pattern of reference and the whitephase substance. Shadowed area indicates C-S-H phases. $\mathrm{CH}$ : portlandite, $\mathrm{Ca}(\mathrm{OH})_{2}$; CSH: calcium silicate and C-S-H gel; E: ettringite; G: gypsum; C: calcite, $\mathrm{CaCO}_{3}$

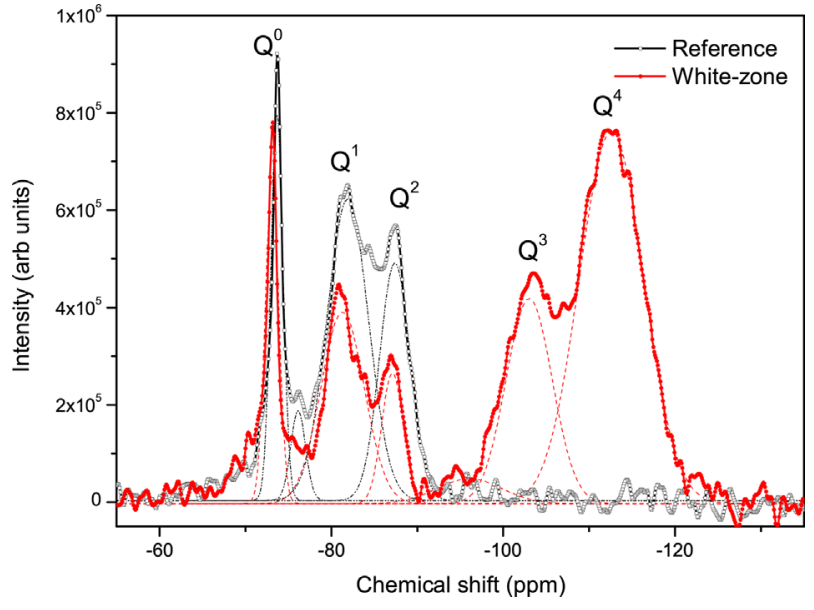

FIGURE $10{ }^{29} \mathrm{Si}$ solid state spectra of reference sample and white substance from the ring-pattern area. $Q^{0}$ peak is assigned to a monomer, $Q^{1}$ to dimer, $Q^{2}$ to chain, $Q^{3}$ to branched structures, and $Q^{4}$ to networked structures

were 3.2 and 2.7, respectively, indicating that the chain lengths contained in the C-S-H gel were also reduced.

To summarize the results from XRD and NMR, it can be suggested that the formed white zone was a silica-gel-like phase, which was amorphous and had developed branched and networked structures. The formation of such a phase was due to a high degree of calcium depletion as a consequence of the impressed current.

\section{5 | Movement of chloride ions}

Figure 11 illustrates the chloride profiles of Acc6 and the reference samples soaked in tap water and $3 \% \mathrm{NaCl}$ solution for 35 days.

Cement clinker contained $0.01 \mathrm{wt} \%$ of chloride, which was the only chloride source in this case of tap water

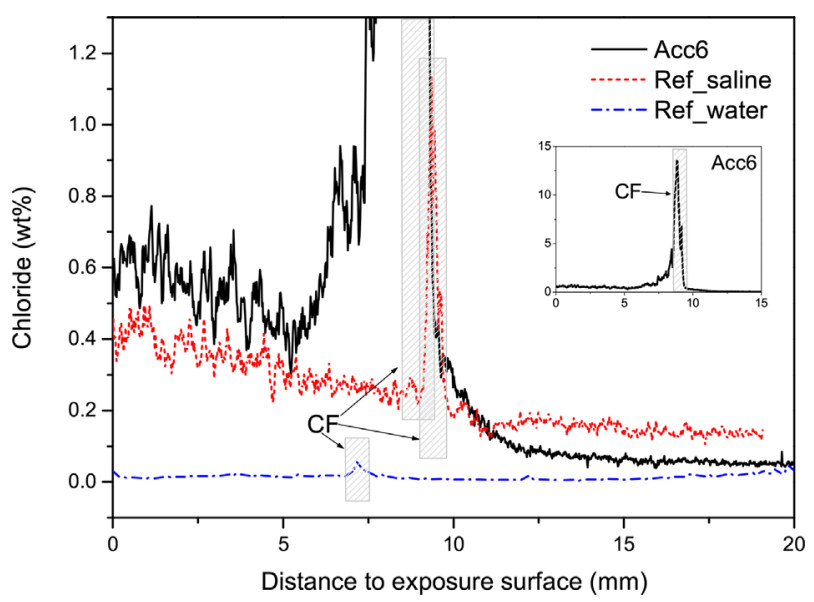

FIGURE 11 Chloride profiles of reference samples immersed in tap water and $3 \% \mathrm{NaCl}$ solution. Shadowed areas indicate the location of the CFRP anode 


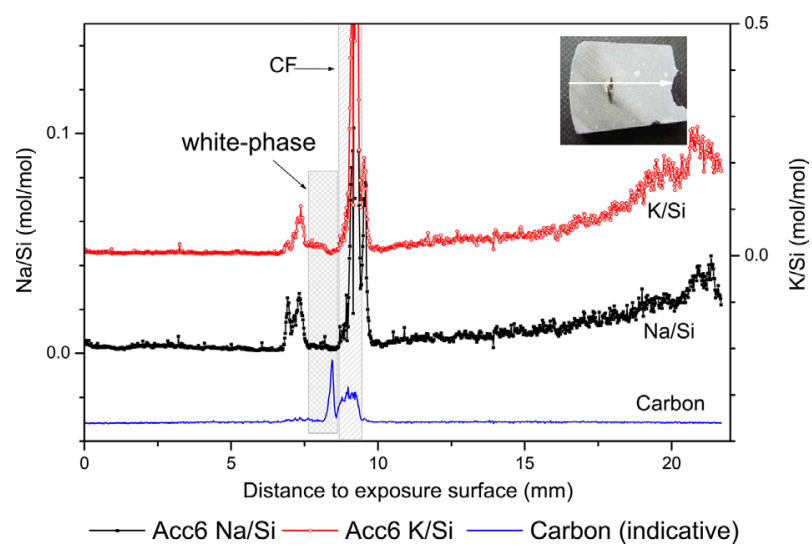

FIGURE 12 Sodium, potassium, and carbon profiles of accelerated sample Acc6 subjected to a current density of $2 \mathrm{~A} / \mathrm{m}^{2}$ for 35 days in $3 \% \mathrm{NaCl}$ solution. All molar concentrations are normalized to silica. Shadowed areas indicate the appearance of a white phase and the location of the CFRP anode. An image of sample Acc6 is displayed in the corner. The arrow indicates the location of the line-scanning and its direction

immersion. At the position where the CFRP anode was located $(x=7 \mathrm{~mm})$, the content of the chloride was slightly increased, to about $0.06 \%$.

In the case of $3 \% \mathrm{NaCl}$ solution immersion, the chloride in the HCP showed a classic diffusion profile. At the position of the CFRP anode $(x=9 \mathrm{~mm})$, the chloride content was much higher than that in the HCP. This could be explained by more voids or micro-gaps existing in the anode-paste interface, which would be equivalent to a higher porosity at the interface, resulting in more chlorides than that in the surroundings.

An Acc6 sample was taken from the top part close to the level of the submerging solution, in Figure 5C. The chloride profile was a result of a combined effect of diffusion and migration. Between the exposure surface and $x=5 \mathrm{~mm}$, the transport mechanism was diffusion and the chloride content was higher than that of the reference in salt solution. The CFRP anode was located at a position between 8.5 and $9.5 \mathrm{~mm}$, where the chlorides came close to the anode, and the transport mechanism was dominated by migration. Therefore the chlorides were forced to move towards the anode and the chloride content was about 10 times higher than the reference in salt solution, as shown in the inset graph in Figure 11.

\section{6 | Movement of alkali ions}

Figure 12 shows the distribution of sodium ions $\left(\mathrm{Na}^{+}\right)$and potassium ions $\left(\mathrm{K}^{+}\right)$between the exposure surface $(x=0 \mathrm{~mm})$ and the steel reinforcement $(x \approx 22 \mathrm{~mm})$. Alkalies accumulated at the cathode site due to migration in which the steel as cathode produces hydroxide $\left(\mathrm{OH}^{-}\right)$and attracted positive ions. The overall effect of alkali accumulation at the cathode was also confirmed. Apparently this result was different from the modeling using low current densities. ${ }^{[12]}$ In Peelen's model, ${ }^{[12]}$ the overall flux of sodium ions was found to be zero at $10 \mathrm{~mA} / \mathrm{m}^{2}$ for 100 years (the calculation of potassium ions was not included). These two results are not in conflict, because they indicate that the choice of current density is in fact an important key factor in regard to designing and evaluating an ICCP system. At a high current density, the mass transport is dominated by migration while diffusion can be neglected. However, at a low current density, the mass transport is governed by the coupled processes of migration and diffusion. A concentration gradient is built up by migration and then back-diffusion takes places, which results in a overall zero flux of sodium ions, as discovered by modeling. ${ }^{[12]}$

The accumulation of alkalis appeared near the white zone as well. The explanation of this phenomenon could be as follows. The silica-gel-like white zone was negatively charged after calcium was leached, due to hydrogen formation and migration. When the experiment

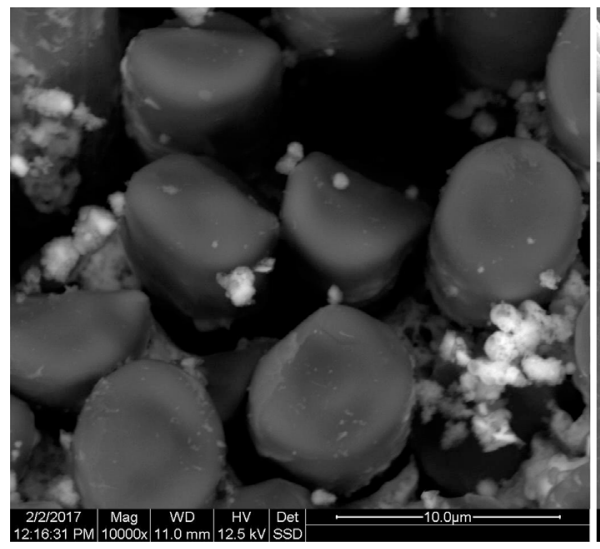

(a) Image of the cross-section of CFRP.

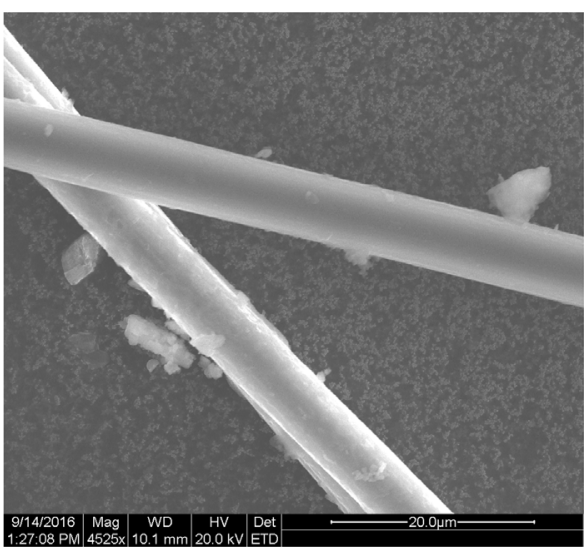

(b) Image of two single fibers with smooth surface.

FIGURE 13 CFRP anode after accelerated test. The white crystals appearing in the corner in (a) and next to the fiber in (b) are potassium $\left(\mathrm{K}^{+}\right)$and chloride $\left(\mathrm{Cl}^{-}\right)$enriched phases. (a) Image of the cross-section of CFRP. (b) Image of two single fibers with smooth surface 
was terminated and the electrical potential disappeared, alkali ions immediately diffused towards the white zone to keep electroneutrality because of their high ionic mobilities. As a consequence of migration and backdiffusion when the ICCP was terminated, alkali peaks next to the white zone were observed, as shown in Figure 12.

\subsection{Degradation of the CFRP anode}

Figure 13 shows the SEM results of the undamaged carbon fiber after the accelerated test. The polymer matrix disappeared, leading to a higher porosity at the anode. During the drying process of preparation, pore solutions evaporated through the pores between the fibers and the ions in it eventually crystallized. The white crystals appearing around the carbon fiber were potassium $\left(\mathrm{K}^{+}\right)$and chloride $\left(\mathrm{Cl}^{-}\right)$enriched phases.

\section{4 | CONCLUDING REMARKS}

This study focused on the microstructure analysis of the paste-anode interface using an accelerated method (current density of 2 and $4 \mathrm{~A} / \mathrm{m}^{2}$ of anode surface) and an innovative CFRP material as anode. The results showed that a total charge density of $6 \times 10^{6} \mathrm{C} / \mathrm{m}^{2}$ can cause an average thickness of calcium dissolution of $0.34 \mathrm{~mm}$ around the anode within 35 days of accelerated tests, or an equivalent operating time of 30 years at $4 \mathrm{~mA} / \mathrm{m}^{2}$ (of anode surface) according to a linear conversion from the accelerated tests.

A white zone was formed around the anode, in which the $\mathrm{C} / \mathrm{S}$ ratio decreased from 3.2 to 1.3 . The formation of this white zone was due to a severer calcium dissolution caused by electrochemical reactions at the anode. The white-zone substance was, to a large extent, constituted of branched and networked structures and the C-S-H gel became polymerized or more amorphous. The resistivity was also increased, mainly because of the formation of the white zone.

The accumulation of chloride ions at the anode and alkalies at the cathode was also confirmed by LA-ICP-MS analysis. It has also been proven that LA-ICP-MS is a reliable tool to analyze major and trace elements in the HCP and concrete materials.

The carbon fiber embedded in the specimen remained undamaged under $4 \mathrm{~A} / \mathrm{m}^{2}$, while the polymer matrix was degraded due to oxidation, which implies that CFRP can be used as an anode material for ICCP applications.

The conversion from an accelerated test to normal operation has been taken to be linear in this study, which obtained promising outcomes that could be suitable for a long-term ICCP evaluation although it might overestimate the damage to some extent.

\section{ACKNOWLEDGMENT}

The authors thank Dr. Thomas Zack from University of Gothenburg with the help of LA-ICP-MS instrument. This research was supported the Swedish Research Council FORMAS (grant number 249-2011-1520) and European Union's Research and Innovation funding program FP7 (project DOSECOPS).

\section{ORCID}

Emma Q. Zhang (iD http://orcid.org/0000-0002-7504-6148

\section{REFERENCES}

[1] L. Bertolini, F. Bolzoni, A. Cigada, T. Pastore, P. Pedeferri, Corros. Sci. 1993, 35, 1633.

[2] N. C. Webb, Construction Building Mater. 1992, 6, 179.

[3] A. A. Sohanghpurwala, Cathodic protection for life extension of existing reinforced concrete bridge elements, NCHRP Synthesis of Highway Practice Number 398. Transportation Research Board, 2009.

[4] L. Bertolini, F. Bolzoni, P. Pedeferri, L. Lazzari, T. Pastore, J. Appl. Electrochem. 1998, 28, 1321.

[5] P. Pedeferri, Construction Building Mater. 1996, 10, 391.

[6] T. Eichler, B. Isecke, G. Wilsch, S. Goldschmidt, M. Bruns, Mater. Corros. 2010, 61, 512.

[7] K. Davies, J. Broomfield, Cathodic Protection of Steel in Concrete and Masonry, Vol. 41, 2nd ed., CRC Press, Boca Raton, FL 2013, pp. 41-55.

[8] K. Haga, M. Shibata, M. Hironaga, S. Tanaka, S. Nagasaki, J. Nucl. Sci. Technol. 2002, 39, 540.

[9] F. Matsushita, Y. Aono, S. Shibata, Cem. Concr. Res. 2004, 34, 1251.

[10] R. Polder, T. Nijland, W. Peelen, L. Bertolini, "Acid formation in the anode/concrete interface of activated titanium cathodic protection systems for reinforced concrete and the implications for service life, " in 15th International Corrosion Congress (ICC), Granada, Spain, 22-27 September, 2002.

[11] R. Polder, W. Peelen, J. Leggedoor, G. Schuten, Microscopy study of the interface between concrete and conductive coating used as anode for cathodic protection, 2003, European Federation of Corrosion Publications Number 38, ch. 22, pp. 277-287.

[12] W. Peelen, R. Polder, E. Redaelli, L. Bertolini, Mater. Corros. 2008, 59, 81.

[13] S. F. Brena, R. M. Bramblett, S. L. Wood, M. E. Kreger, Struct. J. 2003, 100, 36 .

[14] P. Lambert, C. Van Nguyen, P. S. Mangat, F. J. O'Flaherty, G. Jones, Mater. Struct. 2015, 48, 2157.

[15] J.-H. Zhu, G. Guo, L. Wei, M. Zhu, X. Chen, Materials 2016, 9 , 103.

[16] L. Tang, E. Q. Zhang, Y. Fu, B. Schouenborg, J. E. Lindqvist, Mater. Corros. 2012, 63, 1119.

[17] C. Van Nguyen, P. Lambert, P. Mangat, F. O'Flaherty, G. Jones, International Scholarly Research Network ISRN Corros. 2012, Article ID 814923.

[18] C. V. Nguyen, P. S. Mangat, P. Lambert, F. J. O. Flaherty, G. Jones, Concrete Repair, Rehabilitation and Retrofitting III, CRC Press, Boca Raton 2012, pp. 1179-1185. 
[19] H. Sun, S. A. Memon, Y. Gu, M. Zhu, J.-H. Zhu, F. Xing, Mater. Struct. 2016, 49, 5273.

[20] H. Sun, L. Wei, M. Zhu, N. Han, J.-H. Zhu, F. Xing, Construction Building Mater. 2016, 112, 538.

[21] J.-H. Zhu, L. Wei, M. Zhu, H. Sun, L. Tang, F. Xing, Materials 2015, 8, 4316.

[22] J.-H. Zhu, L. Wei, Z. Wang, C. K. Liang, Y. Fang, F. Xing, Construction Building Mater. 2016, 120, 275.

[23] H. Sun, G. Guo, S. A. Memon, W. Xu, Q. Zhang, J.-H. Zhu, F. Xing, Composites Part A 2015, 78, 10.

[24] J. Chang, Cem. Concr. Compos. 2002, 32, 657.

[25] NACE SP0290-2007, "Impressed current cathodic protection of reinforcing steel in atmospherically exposed concrete structures," 2007.

[26] K. P. Jochum, U. Weis, B. Stoll, D. Kuzmin, Q. Yang, I. Raczek, D. E. Jacob, A. Stracke, K. Birbaum, D. A. Frick, Geostandards Geoanalytical Res. 2011, 35, 397.

[27] J. J. Kim, M. K. Rahman, M. M. Reda Taha, Appl. Nanosci. 2012, $2,445$.
[28] K. Kurumisawa, T. Nawa, H. Owada, M. Shibata, Cem. Concr. Res. 2013, 52, 190.

[29] G. Le SaoÛt, E. Lécolier, A. Rivereau, H. Zanni, Cem. Concr. Res. 2006, 36, 428.

[30] I. G. Richardson, Cem. Concr. Res. 1999, 29, 1131.

[31] A. Babaahmadi, Durability of Cementitious Materials in LongTerm Contact With Water, Chalmers University of Technology, Gotheborg 2015.

[32] X. Cong, R. J. Kirkpatrick, Adv. Cem. Based Mater. 1996, 3, 144.

How to cite this article: Zhang EQ, Tang L, Bernin D, Jansson H. Effect of the paste-anode interface under impressed current cathodic protection in concrete structures. Materials and Corrosion. 2018;1-13. https://doi.org/10.1002/maco.201709908 